\title{
MEDIDA DE SEGURANÇA E PERICULOSIDADE: A CONTRADIÇÃO DA PERSISTÊNCIA DO ENFOQUE ETIOLÓGICO NO ESTADO DEMOCRÁTICO DE DIREITO BRASILEIRO
}

\section{RESUMO}

Roberto Carvalho Veloso* Gabriel Silva de Abreu**

Pretende-se enfrentar neste artigo o problema da aparente contradição existente entre o instituto da medida de segurança e a sistemática atual da periculosidade. Utilizando o método hipotético-dedutivo, em abordagem jurídico-científica, objetiva-se analisar criticamente o fundamento da noção de periculosidade, arraigado no enfoque etiológico da Criminologia Positivista e dissertar acerca da aplicação das medidas de segurança no Estado Democrático de Direito, apresentando como resultado que a periculosidade apresenta diversas inconsistências com a atual sistemática do ordenamento jurídico brasileiro, no qual há limitação do poder punitivo estatal.

Palavras-chave: Medida de segurança; Periculosidade; Etiologia; Criminologia; Limites.

\section{SECURITY MEASURE AND PERICULOSITY: THE CONTRADICTION IN THE PERSISTENCE OF AN ETIOLOGICAL APPROACH IN THE BRAZILIAN DEMOCRATIC STATE OF LAW}

\begin{abstract}
The aim of this paper is to discuss the problem of the apparent contradiction existing between the institute of the security measure and the current systematic surrounding periculosity. With the application of the hypothetical-deductive method, the objective is to analyze, critically, the foundation of the notion of periculosity, rooted in the etiological paradigm of Positivist Criminology, and to dissect about the application of the security measures in the Democratic State of Law, providing as a result that the concept of periculosity presents several inconsistencies with the current systematic of Brazil's legal order, that limits the state's punitive power.
\end{abstract}

Keywords: Security measure; Periculosity; Etiology; Criminology; Limits.

\section{INTRODUÇÃO}

Para o presente estudo, volta-se a atenção à importante temática referente ao instituto da medida de segurança, meio pelo qual o direito, utilizando o critério da periculosidade, lida com pessoas portadoras de doença mental que cometem ilícitos penais. $\mathrm{O}$

\footnotetext{
* Doutor em Direito pela Universidade Federal de Pernambuco (2008), Mestre em Direito pela Universidade Federal de Pernambuco (2002) e Graduado em Direito pela Universidade Federal do Piauí (1987). Professor e Pesquisador da UniCEUMA. Professor Associado da Universidade Federal do Maranhão. Juiz Federal no Maranhão. Coordenador do Mestrado em Direito da UFMA. velosorc@uol.com.br

*** Mestrando do Programa de Pós-Graduação em Direito e Instituições do Sistema de Justiça da Universidade Federal do Maranhão. gabriel.silvabreu@ hotmail.com

CONPEDI LAW REVIEW | EVENTO VIRTUAL | v. 6 | n. 1 | p. 175 - 195 | JAN - DEZ | 2020 
problema da pesquisa, que justifica sua realização, consiste na seguinte questão: em que medida a fundamentação teórica historicamente construída para o instituto jurídico da medida de segurança está em concordância com as bases teóricas do direito penal, no âmbito do Estado Democrático de Direito brasileiro?

O objeto da pesquisa consiste, então, no paradigma da periculosidade como conceito que, pela dogmática da lei, determina e orienta a aplicação das medidas de segurança. Apresenta-se na centralidade da pesquisa a hipótese de que o instituto jurídico da medida de segurança não apresenta uma fundamentação que se encontre em concordância com as bases teóricas de categoria constitucional do direito penal no âmbito do Estado Democrático de Direito brasileiro, referentes à teoria do crime e ao princípio da culpabilidade. Como se verifica, tal questão se apresenta como de extrema relevância e latente, tendo em vista que trata dos próprios fundamentos da ação estatal.

Em sede de metodologia, a pesquisa, de natureza qualitativa, utiliza-se da abordagem jurídico-científica $^{1}$ e, de modo geral, do método hipotético-dedutivo ${ }^{2}$, no qual se tem o processo de identificação do problema, construção de uma resposta teórica que constitui a hipótese, e sua aplicação, com a resposta ao problema examinado. Procedimentalmente, são aplicados os métodos sociojurídico-crítico e jurídico-compreensivo, e os trabalhos se valem das técnicas de pesquisa descritiva e analítica.

Busca-se, como objetivo geral, demonstrar que, pela racionalidade do ramo jurídico em questão, o instituto da medida de segurança, com fundamentação teórica de cunho etiológico, contradiz o direcionamento que o ordenamento jurídico-constitucional confere ao direito penal. Em sede de objetivos específicos, pretende-se discorrer, primeiro, sob a abordagem sociojurídica-crítica, acerca da construção histórica da noção de periculosidade, de modo a sintetizar a problemática, em um recorte temporal e temático centralizado na Criminologia Positivista e na sua crítica.

Após, pretende-se discorrer, em abordagem jurídico-compreensiva, sobre a relação entre Estado Democrático de Direito, direito penal, e teoria do delito, sendo o direito penal compreendido, no âmbito dessa relação, como instrumento de controle social e

\footnotetext{
${ }^{1}$ A investigação jurídico-científica parte de indagações conceituais ou de base empírica, dirigidas para a obtenção de conhecimento teórico-especulativo ou de natureza teórica, mas destinado a eventual aplicação concreta (FONSECA, 2009, p. 9-11).

${ }^{2}$ Marconi e Lakatos (2003, p. 106), resumidamente, pontuam que o método "se inicia pela percepção de uma lacuna nos conhecimentos, acerca da qual formula hipóteses e, pelo processo de inferência dedutiva, testa a predição da ocorrência de fenômenos abrangidos pela hipótese".
} 
limitação do poder punitivo, de modo que sua teoria fornece a racionalidade para tal desiderato. Segue-se, por último, à aplicação da hipótese como resposta ao problema, com o exame da incompatibilidade da medida de segurança e da noção de periculosidade com os fundamentos do direito penal no Estado Democrático de Direito.

\section{MEDIDA DE SEGURANÇA, PERICULOSIDADE E ENFOQUE ETIOLÓGICO}

Examina-se, por meio da perspectiva sociojurídica-crítica ${ }^{3}$, a construção teórica na qual se insere a ideia do indivíduo perigoso, e na qual foi inaugurado o instituto jurídico da medida de segurança, sendo esse conjunto de teorias agregado no que Baratta (2002) denominou de "enfoque etiológico", acrescentando-se a referência de Andrade (1995), que informa ser esse o paradigma que sofreu modificações pela virada ocorrida a partir da Criminologia Crítica.

Levando em consideração que o objeto de investigação das ciências sociais é histórico ${ }^{4}$, tem-se que a crítica teórica aos fundamentos da medida de segurança apresenta importante conexão com a própria trajetória teórica da Criminologia como ciência, de modo que as bases positivistas desta informaram a dogmática das normas jurídicas que disciplinaram aquele; assim, a crítica do objeto da pesquisa se insere no estudo da relação histórica entre Direito, Criminologia, e Psiquiatria.

\subsection{O desenvolvimento do enfoque etiológico e da periculosidade}

Sabe-se que do Iluminismo do século XVIII partiram premissas de superação das práticas do Absolutismo, buscando-se a modernização das penas - conforme sintetizado na obra de Beccaria (2013) - que operavam, até então, como uma expressão do poder soberano do rei sobre os súditos. Superada a irracionalidade dos suplícios, seguiu-se à compreensão racional da criminalidade como um fenômeno.

\footnotetext{
${ }^{3}$ O método sociojurídico-crítico tem a realidade social como ponto de partida para a construção do tema, o Direito como lugar no campo do conhecimento onde se situa a pesquisa, e a pretensão precípua de realizar o aprofundamento do tema, de modo a buscar suas raízes históricas e sociais (FONSECA, 2009, p. 62-70).

${ }^{4}$ Sobre o tema, Minayo (2009, p. 12-13) afirma que "o objeto das Ciências Sociais é histórico. Isto significa que as sociedades humanas existem num determinado espaço cuja formação social e configuração são específicas. [...] O nível de consciência histórica das Ciências Sociais está referenciado ao nível de consciência histórica social". 
Destarte, seguiu-se com o desenvolvimento da Criminologia como ciência, no âmbito da Escola Positivista ${ }^{5}$, a partir da segunda metade do século XIX, com estudos como os de Lombroso e Ferri, onde as causas da criminalidade são buscadas pelos métodos das ciências naturais, na concepção do crime como relativo à patologia, fator que indica a relação entre Medicina e Direito que se demonstra tão presente no desenvolvimento do Sistema Penal.

Pela perspectiva sociojurídica-crítica, verifica-se que o caminho da Criminologia como conhecimento científico parte, inicialmente, da legitimação da seletividade do poder punitivo. Com uma nova estrutura social, novas teorias são produzidas para, conforme pontua Anitua (2008, p. 132), “justificar um Estado não apenas limitado pela lei, mas também com determinada propensão econômica favorável aos detentores dos meios de produção e [...] repressivo para com aqueles que não têm propriedade".

À racionalidade universal iluminista passa a ser somada a contribuição dada pela ciência natural desenvolvida na Escola Positivista, na segunda metade do século XIX; o Direito Penal, então, no período em que o capitalismo avança para a fase Industrial, passa a ter sua lacuna legitimadora preenchida pela Medicina, de modo que "o médico e seu prestígio preencheram, pouco a pouco, os vazios do igualitarismo burguês e trouxeram as ferramentas para o funcionamento efetivo da sociedade e o controle do homem" (ANITUA, 2008, p.237).

$\mathrm{O}$ ponto de destaque reside no enfoque ou paradigma etiológico, pela qual as causas do crime podem ser identificadas na constituição biopsicológica do criminoso; tese esta que encontrou um expoente simbólico em Lombroso e Ferri, conforme a referência de Andrade (1995, p. 25), tal perspectiva, "partindo do determinismo biológico (anatômicofisiológico) e psíquico do crime e valendo-se do método de investigação e análise próprio das ciências naturais (observação e experimentação) procurou comprovar sua hipótese através da confrontação de grupos não criminosos com criminosos dos hospitais psiquiátricos e prisões".

A criminalidade é entendida como o meio natural de comportamento dos indivíduos que constituem uma minoria anormal e criminosa que perturba a ordem social, cuja proteção é função do direito penal, que intervêm para impedir a lesão a bens jurídicos da mais alta importância social. É neste ponto que reside a noção de periculosidade, principal fator de aplicação da resposta jurídica aos criminosos anormais. Por essa visão, o direito penal atua sobre uma realidade ontológica e pré-constituída, referente ao delito natural,

\footnotetext{
${ }^{5}$ Foucault (2014, p. 248) completa o raciocínio: "Nesse novo saber importa qualificar 'cientificamente' o ato enquanto delito e principalmente o indivíduo enquanto delinquente. Surge a possibilidade de uma criminologia". CONPEDI LAW REVIEW | EVENTO VIRTUAL | v. 6 | n. 1 | p. 175 - 195 | JAN - DEZ | 2020 
reconhecendo a realidade e positivando as normas que combaterão o problema (ANDRADE, 1995, p. 25).

Não obstante, desde meados do século XX, a análise do fenômeno da criminalidade foi adquirindo característica de análise social, de modo a desvelar a relação entre os modelos punitivos e o controle da população, localizada no contexto maior da estrutura social, de modo que a, paulatinamente, se construir a crítica ao sistema penal e às respectivas teorias de tal época, tendo-se, então, na segunda metade do mesmo século, posicionamentos como o movimento antimanicomial e o abolicionismo penal (CARVALHO, 2014, p. 147-148).

Assim, em momento posterior, por influência da Sociologia Criminal, o foco de análise da criminalidade se deslocou do paradigma etiológico para o paradigma do labeling approach, com a concepção de que o desvio é uma realidade social, construído na experiência humana, através de processos de reação e etiquetamento de grupos desviantes ${ }^{6}$. O enfoque da reação social, após grande aprofundamento teórico, constituiu base para a Criminologia Crítica (BARATTA, 2002, p. 86-89).

Finalizando a breve abordagem histórica, afirma-se já ocorreu, no ordenamento pátrio, uma mudança de paradigma no tratamento da saúde mental, referente à Lei n. ${ }^{\circ}$ 10.216/2001, resultado do movimento de reforma psiquiátrica, da luta antimanicomial. Branco (2019, p. 180) observa que, ainda assim, o sistema penal brasileiro não recebeu reformas no tratamento do inimputável que comete ilícitos penais, continuando a ignorar os preceitos reformadores, e mantendo o paradigma positivista sobre o qual se discorreu.

\subsection{A crítica ao enfoque etiológico e à noção de periculosidade da medida de segurança}

A partir do direcionamento da Criminologia Crítica $^{7}$, pode-se verificar que na segunda metade do século XIX houve uma confluência da Psiquiatria com o direito penal. Há uma modificação na definição da loucura, que apresenta precedentes iniciais desde meados do

\footnotetext{
${ }^{6}$ Em somatório, Andrade (1995, p. 29) pontua: “Ao afirmar que a criminalidade não tem natureza ontológica, mas social e definitorial e acentuar o papel constitutivo do controle social na sua construção seletiva, o labelling desloca o interesse cognoscitivo e a investigação das 'causas' do crime e, pois, da pessoa do autor e seu meio e mesmo do fato-crime, para a reação social da conduta desviada, em especial para o sistema penal".

${ }^{7}$ Sobre tal direcionamento, Baratta (2002, p. 151), propõe a superação da ideologia da defesa social, onde se localiza o enfoque etiológico, de modo a situar os elementos da questão criminal no quadro da estrutura social. 
século XVIII, nos quais se dá a judicialização de tais questões, realizada no âmbito do positivismo científico, criminológico e jurídico (MACHADO e MESSERE, 2019).

Antes disso, a questão da loucura se mostrava pontual e não indicava a hipótese de sujeitos perigosos para a sociedade, como se tem hodiernamente; no entanto, a partir desse momento histórico, as legislações ocidentais passaram a apresentar a possibilidade de punir os indivíduos por seu caráter perigoso, com fins de fornecer tratamento, eis que a delinquência era vista como resultado natural de condições biopsicológicas (NETTO e NAVES, 2018).

A partir do momento em que a Psiquiatria ingressa no campo jurídico, a atuação privilegiada do conhecimento médico se torna preponderante no que diz respeito ao status dos indivíduos. A legitimação da atuação do saber médico implicou na delimitação do objeto de seu controle, com o estabelecimento de uma nova classe de sujeitos, sendo esses os sujeitos perigosos, que passam a constituir um objeto privilegiado de intervenção (SILVA et al, 2018).

O saber psiquiátrico dos especialistas sobre a loucura informa a operacionalização do Direito Penal - a perícia médica não apenas reconhece a loucura, mas também confirma a existência da suposta periculosidade, permitindo a submissão dos sujeitos perigosos à ordem da lei, em caráter curativo e disciplinar, o que somente se autoriza encerrar com a verificação da cessação de tal periculosidade (BRISSET e JUNCAL, 2018).

Com isso, é na concepção positivista que se tem o cerne e a limitação do instituto da medida de segurança: se, por um lado, a culpabilidade constitui a premissa fundamental de aplicação da sanção penal voltada à pena, será a periculosidade, por outro lado, que constituirá o pressuposto para a imposição dessa outra espécie de sanção penal, consubstanciada na medida de segurança (CAETANO, 2017).

A periculosidade, confluência da Psiquiatria com o Direito, se encontra na intersecção da estigmatização da loucura com a seletividade: o indivíduo é rotulado como de natureza essencialmente criminosa. Em correspondência, a resposta jurídica conferida à conduta atende a uma razão contraditória que pretende ser tratamento e, ao mesmo tempo, é executada por meio de uma estrutura de lógica punitiva.

Desse modo, à medida de segurança é conferida a função curativa ou tratativa da patologia que dá ao indivíduo o caráter de perigoso. Sobre o tema, Andrade (1995, p. 25-26) pontuou o papel de representações associadas às noções de determinismo, criminalidade ontológica, periculosidade, anormalidade, tratamento e ressocialização, que são complementares e se fecham em um círculo que conforma a concepção geral de criminalidade 
que "se encontra, há um século, profundamente enraizada nas agências do sistema penal e no senso comum".

Se, para a Escola Positiva, a periculosidade constituída característica inerente ao criminoso, posteriormente, com a mudança de paradigmas ou enfoques, a periculosidade ficou reservada somente ao louco infrator. Pelas reformas legislativas, o sistema duplo binário, que apresentava a possibilidade de as duas espécies de sanções serem aplicadas ao indivíduo imputável em conformidade com sua periculosidade, foi substituído, especificamente pela reforma de 1984, pelo sistema vicariante, no qual a periculosidade é atributo exclusivo do louco, não mais informando o processamento do fato cometido pelo imputável (CAETANO, 2017).

O conceito de periculosidade, que antes norteava toda a política criminal, sendo igualmente aplicável a imputáveis, foi superado pelo avanço na teoria do delito, com o prestígio da ideia de culpabilidade, restando, entretanto, a noção de periculosidade, no sistema vicariante, restrita ao campo no qual o Direito Penal permaneceu aliado à Psiquiatria: no controle dos portadores de transtornos mentais que cometem atos ilícitos.

Desse modo, tais indivíduos são classificados numa categoria especial, diferenciada do "doente mental" e do "transgressor", sendo a resposta jurídica uma dupla estigmatização - doentes mentais e, ao mesmo tempo, criminosos, “congregando, a um só tempo, dois dos piores insuportáveis para a sociedade, a loucura e o crime", sendo esses sujeitos "designados à vida nos hospitais de custódia que, por sua vez, são lócus do pior do pior, por recolherem simultaneamente o pior do estigma com o pior da segregação" (SILVA et al, 2018).

A análise crítica do objeto de investigações aponta que a operacionalização da medida de segurança apaga indivíduos do convívio social, através de mecanismos que impedem, pela maior quantidade de tempo possível, sua circulação na sociedade, de modo que o instituto se conforma a padrões de exclusão e estigmatização (NETTO e NAVES, 2018, p. 210). Na mesma linha, Branco (2017, p. 30) aponta que "a periculosidade criminal e a defesa social transformaram-se em polos entre os quais passam a desenvolver-se toda a dinâmica do direito penal”, de modo direcionar a aplicação desse instituto jurídico.

Assim, fazendo referência ao comentário de Caetano (2017, p. 64-65), a periculosidade, que norteia e fundamenta a medida de segurança, é uma herança lombrosiana juridicamente injustificável em seus fundamentos que contradizem as noções normativas e de 
caráter constitucional que direcionam a aplicação do Direito Penal no atual contexto do Estado Democrático de Direito brasileiro.

\section{O DIREITO PENAL NO ESTADO DE DIREITO E A TEORIA DO DELITO}

A perspectiva sociojurídica-crítica revela os problemas que devem ser investigados no estudo do objeto; tomando essa perspectiva como necessária, entende-se, por meio do método jurídico-compreensivo ${ }^{8}$, que o Direito, no contexto do Estado Democrático de Direito, constitui ferramenta capaz de limitar as máculas da desigualdade e da seletividade, através de sua produção e aplicação vinculadas aos direitos fundamentais e ao preceito da dignidade humana, viabilizados pela fórmula da democracia.

A relação entre sociedade civil e Estado dá contexto à aproximação teórica entre poder político e Direito, tendo em vista a experiência normativa que se dá no bojo dessa confluência de categorias. O marco teórico de Bobbio (1997, p. 13) informa que "direito e poder são as duas faces de uma mesma moeda: só o poder pode criar direito e só o direito pode limitar o poder", de modo que se tem, na teoria de base, a importância do Estado de direito para o exercício do poder na sociedade, sendo esse o ponto sobre o qual se discorrerá ${ }^{9}$.

\subsection{O Direito Penal como limitação do poder punitivo no Estado Democrático de Direito}

O desenvolvimento da noção de Estado Democrático de Direito que opera como marco teórico é realizado com referência a Bobbio (1997, p. 149), que verifica que o Estado de direito e a democracia são categorias que, embora intimamente ligadas, não se pressupõem. O Estado de direito diz respeito ao modo de governar, e a democracia, trata da melhor forma de governo, ou seja, de quais e quantos são os governantes.

O Estado de Direito é aquele em que os poderes públicos são regulamentados por normas gerais, e são limitados nos termos da lei, em conformidade com a doutrina da

\footnotetext{
${ }^{8}$ Com a referência a Gustin e Dias (2010, p. 25-29), pode-se afirmar que a investigação de tipo jurídicocompreensivo ou jurídico-interpretativo, utiliza-se do "procedimento analítico de decomposição de um problema jurídico em seus diversos aspectos, relações e níveis”.

${ }_{9}^{9} \mathrm{O}$ poder intervém na criação e aplicação das normas, e na produção de efeitos jurídicos, e direitos fundamentais são responsáveis por limitar o poder, autorizando-o e regulando-o; o poder exige o direito para se tornar legítimo, e o direito exige o poder para ser efetivo; desse modo, afirma-se que norma jurídica e poder compõem duas faces da mesma moeda. No âmbito da Teoria do Direito, pode-se afirmar que o poder do qual depende o direito constitui a soberania, e o direito do qual depende o poder se refere à norma fundamental (BOBBIO, 2000, p. 239 e 250).
} 
superioridade do governo das leis sobre o governo dos homens, distinguindo-se daquele modo de governo no qual impera a arbitrariedade das decisões tomadas pelo governante. A preferência pelo governo das leis trata do exercício do poder mediante normas gerais e abstratas, características estas que são intrínsecas à noção de lei, de modo a se garantir, efetivamente, valores fundamentais e ideais de igualdade, segurança e liberdade (BOBBIO, 1997, p. 18).

Pelo referencial teórico, a definição mínima de democracia tem um caráter procedimental, e aponta que "por regime democrático entende-se primariamente um conjunto de regras de procedimento para a formação de decisões coletivas, em que está prevista e facilitada a participação mais ampla possível dos interessados", de modo que se tem "um conjunto de regras (primárias ou fundamentais) que estabelecem quem está autorizado a tomar as decisões coletivas e com quais procedimentos", sendo esse poder-direito de decisão atribuído a um número muito elevado de integrantes (BOBBIO, 1997, p. 12-18).

Desse modo, a participação ampla da população na tomada de decisões coletivas é uma das marcas da democracia, sendo outra a existência de uma experiência normativa que trate do procedimento dessa tomada de decisões. Por isso, é fundamental o respeito a direitos de liberdade e igualdade, cuja associação configura pressuposto da democracia: se exigem critérios de igualdade para a participação dos indivíduos, e as liberdades, por exemplo, de voto, de expressão, de reunião e de associação (CADEMARTORI et al, 2006).

Nessa perspectiva, o Estado Democrático de Direito constitui uma necessária aproximação do governo das leis à participação da vontade geral na definição das normas. Partilha-se da concepção de que "o governo das leis celebra hoje o próprio triunfo na democracia", entendida, em linhas gerais, como "um conjunto de regras (as chamadas regras do jogo) para a solução dos conflitos sem derramamento de sangue”, marcado, então, pelo rigoroso respeito a tais regras; a democracia representa, então, o governo das leis por excelência (BOBBIO, 1997, p. 169).

Desse modo, torna-se possível afirmar que o aprofundamento nos fundamentos teóricos do ordenamento em vigor é capaz de oferecer resposta ao problema evidenciado. Sendo o direito entendido como limite ao arbítrio oriundo da desigualdade de poder, o Direito Penal torna-se, então, instrumento de limitação do poder punitivo estatal, capaz de garantir os direitos fundamentais em face dos arbítrios seletivos do exercício do jus puniendi. Faz-se referência ao comentário de Zaffaroni (2014, p. 81), que afirma, com bastante clareza, que "a 
discriminação no exercício do poder punitivo é uma constante derivada de sua seletividade estrutural".

Entende-se, então, que o poder punitivo é seletivo e que a criminalidade decorre de um processo de criminalização, perspectiva na qual Baratta (2002, p. 244) aponta que a criminalização é necessária em relação a comportamentos efetivamente lesivos, dotados de negatividade social, e perpassa pela definição do desvio, pela ação do legislador na criminalização primária, ao definir os ilícitos penais, e pela aplicação das definições legais de delito, pela ação do sistema penal, na criminalização secundária.

Nesse ínterim, pode-se afirmar que a atividade de participação política decorrente do fortalecimento da democracia conduz a um ordenamento jurídico-penal guiado pelos princípios que norteiam o Estado Democrático de Direito, e atento às especificidades do enfrentamento a comportamentos socialmente negativos; as políticas criminais, nesse contexto, constituirão instrumentos de transformação social, e não de opressão dos menos favorecidos. Destarte, a participação ampla e efetiva da população na tomada de decisões coletivas possibilita o controle do poder disponibilizado aos seus representantes (GUIMARÃES, 2013).

O direcionamento desse referencial teórico adotado segue a perspectiva de Guimarães (2007, p. 317), pela qual se busca uma construção teórica do Direito Penal que “reconheça todas as mazelas apresentadas pela Criminologia Crítica e que, a partir desse reconhecimento, pautada no respeito aos princípios e garantias a que faz jus a pessoa humana, se reconstrua dia após dia", de modo a objetivar a diminuição da injustiça social, conforme os preceitos constitucionais que permeiam o direito.

\subsection{A fundamentação do Direito Penal oriunda da teoria do delito e da culpabilidade}

Estabelecido o papel do Direito Penal como expressão do Estado Democrático de Direito e limitador da seletividade do poder punitivo, o instituto jurídico da medida de segurança será analisado nas contradições apresentadas em face da sistemática jurídica estudada. Para isso, segue-se à breve descrição da teoria que informa a dogmática penal, e se conforme ao contexto maior do ordenamento jurídico-constitucional.

Pertinente, aqui, a pontuação de Santos (2014, p. 71), que observa que a teoria do fato punível constitui “o segmento principal da dogmática penal, o sistema de conceitos 
construído para descrever o Direito Penal, como setor do ordenamento jurídico que institui a política criminal - rectius, a política penal - do Estado, o programa oficial de retribuição e de prevenção da criminalidade".

O conceito analítico de crime $^{10}$, que pauta a construção do direito penal, gravita em torno de uma teoria tripartite, que divide os elementos constitutivos do crime em tipicidade, ilicitude e culpabilidade. Os dois primeiros elementos dizem respeito à conduta analisada, enquanto que o terceiro trata de um juízo feito sobre o agente. Nesse construto teórico, a imputabilidade penal se encontra inserida na análise da culpabilidade e consiste, em síntese, na aptidão de um indivíduo para ser culpável, ou seja, responsabilizado por uma conduta que tomou, conforme se tem no artigo 13 do Código Penal.

Com referência a Zaffaroni e Pierangeli (2011, p. 348-349), pode-se notar que a teoria que determina o modo pelo qual o Direito Penal processa o fato punível surge de uma necessidade de aproximar a noção de delito à realidade do conteúdo da vontade da conduta humana, de modo que "o injusto é um juízo de desvalor do ato e a culpabilidade a reprovação que deste ato desvalorado se faz ao autor, por ter tido a possibilidade exigível de atuar de maneira diversa".

A conduta humana é consciente e voluntária, por ter uma finalidade. Logo, se a conduta é inconsciente ou involuntária, ela não poderia ter sido evitada. Se ela é voluntária e consciente, e tem como finalidade a lesão a um bem jurídico, ela será dolosa, intencional; se a conduta, mesmo não visando à lesão de um bem jurídico, foi responsável pela lesão, por ter quebrado uma expectativa de normalidade, ela será, então, culposa. Caso não haja nem culpa nem dolo, então também não poderia ter sido a lesão ao bem jurídico evitada.

Então, com a teoria finalista da ação ${ }^{11}$ de Welzel, que influenciou as modificações legislativas ocorridas nos dispositivos que tratam do tema, não se fala em "culpa da pessoa", mas em "dolo ou culpa da conduta", características que, se ausentes, descaracterizam a voluntariedade, a consciência, e a finalidade do ato, descaracterizando a própria conduta. Se não há, voluntaria e conscientemente, a intenção dirigida a um fim ou a construção situacional que gera o fim, ainda que diretamente intencional, então não há conduta que deva ser

\footnotetext{
${ }^{10}$ Cunha (2016, p. 176) observa que "prevalece, hoje, que, sob o enfoque analítico, crime é composto de três substratos: (i) fato típico, (ii) ilicitude (ou antijuridicidade) e (iii) culpabilidade. Presentes os três, o direito de punir do Estado se concretiza, surgindo a punibilidade (não é substrato do crime, mas sua consequência jurídica) ".

${ }^{11}$ Veloso (2011, p. 169) pontua que, com a concepção de Welzel, “estava lançada a ideia normativa pura da culpabilidade, composta dos seguintes elementos: a imputabilidade, a consciência potencial da ilicitude e a exigibilidade de conduta diversa, nas circunstâncias, porque o dolo e a culpa migraram para o tipo".
} 
penalmente punida; mesmo o agente tendo causado o resultado, sua conduta não configurará o tipo penal (SANTOS, 2014, p. 77-78).

Veloso (2011, p. 137-138) observa que, nessa perspectiva, "uma ação tem que infringir de modo determinado a ordem da comunidade e tem que ser típica e antijurídica e suscetível de reprovação ao autor que como pessoa responsável, necessita ser culpável”, e assevera que "em verdade, não há Direito penal sem culpabilidade, quanto mais crime", ressaltando-se que a culpabilidade é fator-chave de aplicação da sanção penal, tendo, em nosso ordenamento, categoria constitucional, configurando "uma medida do direito de punir do Estado ou uma justificação interna para a aplicação da pena".

A questão tratada neste artigo não diz respeito, especificamente, à imputabilidade penal, do artigo 26 do Código Penal, mas sim, à resposta jurídica que é aplicada a partir do momento em que se reconhece a existência da inimputabilidade. $\mathrm{O}$ ponto de destaque reside na compreensão de que a "periculosidade" configura o principal fator a determinar a sanção penal aplicada em face do agente reconhecido como inimputável, bem como sua duração.

É o que se constata a partir da leitura dos dispositivos do artigo 96 do Código Penal. Nos termos do $\S 1^{\circ}$, a medida de segurança "será por tempo indeterminado, perdurando enquanto não for averiguada, mediante perícia médica, a cessação de periculosidade", devendo ser reestabelecida, conforme o $\S 3^{\circ}$, se o agente pratica, antes do decurso de um ano, "fato indicativa de persistência de sua periculosidade"; outras disposições similares são encontradas no artigo 751 do Código de Processo Penal, e no artigo 175 da Lei de Execução Penal.

Para a presente análise, feita a descrição sintética da teoria e dos dispositivos referentes ao tema, torna-se possível fornecer ao problema uma resposta oriunda da própria racionalidade do direito penal, fundada nos preceitos dos direitos fundamentais, no Estado Democrático de Direito.

\section{AS CONTRADIÇÕES DA MEDIDA DE SEGURANÇA COM O FUNDAMENTO CONSTITUCIONAL DO DIREITO PENAL}

A medida de segurança, fundada na periculosidade oriunda do enfoque etiológico, constitui um resquício da Criminologia Positivista no direito penal, de modo a não ter mais 
lugar como fundamento da resposta estatal à questão do portador de transtorno mental em conflito com a lei.

Se o Estado Democrático de Direito, na perspectiva teórica adotada, é entendido como limitador do poder, então o direito penal, em seu campo de aplicação, também o será, constituindo, especificamente, limitação do poder punitivo; resta compreendido, então, que a função do direito penal se manifesta na contenção do jus puniendi, exercido pelas agências do sistema penal, de modo a se perseguir a segurança jurídica - ou seja, a resolução de conflitos a que visa o direito como um todo (ZAFFARONI e PIERANGELI, 2011, p. 90-91).

A problemática da medida de segurança e da periculosidade evidencia a incompatibilidade do instituto com a sistemática do direito penal: o paradigma etiológico que reside em sua gênese, e constitui característica essencial do instituto, oriunda de concepções ultrapassadas da Criminologia Positivista, aponta a imperiosa necessidade de se analisar a problemática sob a luz do referencial teórico exposto.

Nessa senda, pode-se perceber, primeiro, a contradição da medida de segurança com a sistemática do ordenamento jurídico-constitucional, informado pelo paradigma da Lei da Reforma Psiquiátrica, segundo, a inadequação da medida de segurança à teoria do delito, no que tange à culpabilidade e à proporcionalidade da sanção penal e, terceiro, a imprecisão conceitual do critério-chave de aplicação da medida de segurança.

Sob a égide constitucional, é possível notar incoerências em torno da periculosidade, havendo uma contradição entre sua aplicação e a proteção dos valores de isonomia e proteção de vulnerabilidades constantes na Lei da Reforma Psiquiátrica (ROESLER e LAGE, 2013, p. 42-43).

Analisando o histórico legislativo penal brasileiro, Caetano (2017) verifica que, além de dar o embasamento para as medidas de segurança, a periculosidade se encontra também embutida em outros dispositivos do Código Penal, do Código de Processo Penal e da Lei de Execução Penal, em institutos de nítido fundamento nas teorias lombrosianas, voltadas ao "bandido perigoso", ou ao "preso de alta periculosidade", âmbito no qual se tem a ideia de que a periculosidade é, de fato, um possível atributo humano.

Com vistas à questão da adequação do tratamento de pessoas portadoras de doença mental aos paradigmas da Carta Magna, a Lei da Reforma Psiquiátrica modificou as diretrizes de tratamento em termos de saúde mental; as medidas de internação, em todas as searas do Direito brasileiro, passaram a figurar como exceção, e a definição de um paradigma 
pelo Supremo Tribunal Federal implicou na adequação da norma infraconstitucional referente à duração temporal das medidas de segurança, que passaram a respeitar o limite constitucional das sanções penais, que não podem ser perpétuas.

Pode-se afirmar, nesse âmbito, que o paradigma da Lei da Reforma Psiquiátrica, como expressão do movimento antimanicomial, torna inadequada a noção de periculosidade estampada no artigo 97 do Código Penal, apontando para um padrão de tratamento pautado na prevenção, tendo em vista que, historicamente, a utilização do "tratamento" imposto pela lei tem sempre implicado na sistemática violação de direitos, em medidas de exceção, discriminação, isolamento, e silenciamento ${ }^{12}$.

Sobre o assunto, Netto e Naves (2018, p. 191) identificam uma contradição entre o instituto jurídico da medida de segurança e as previsões da Lei da Reforma Psiquiátrica e da Constituição, referente ao caráter compulsório da internação por medida de segurança e ao seu prazo indeterminado - ponto que, inclusive, já foi enfrentado pelo Supremo Tribunal Federal - de modo a ser possível afirmar que “o termo 'pena' engloba toda forma de restrição de liberdade imposta pelo Estado àquele que descumpriu texto legislativo penal, alcançando, assim, as medidas de segurança" ${ }^{\prime 13}$.

Adiante, no que se refere às bases teóricas do direito penal, sabe-se que, sob o paradigma constitucional, apresentam-se balizas principiológicas como os princípios da fragmentariedade e da ultima ratio, pelos quais só se admite a segregação da liberdade quando esta corresponder à imposição de uma pena privativa de liberdade; a medida de segurança, no entanto, importa em tal segregação, sem apresentar os fundamentos jurídicos necessários para que isso seja viável no Estado Democrático de Direito (COSTA, 2008).

Tal questão se refere à periculosidade, fundamento dogmático da medida de segurança, que permite, de forma excepcional ao princípio da culpabilidade, submeter o portador de doença mental à privação da liberdade, a priori, pelo tempo necessário à cessação dessa periculosidade, em hospital de custódia e tratamento psiquiátrico (BARRETO, 2019).

Os requisitos legais em questão são as condições previstas no caput do artigo 26 do Código Penal, referentes à presença de doença mental ou desenvolvimento mental

\footnotetext{
${ }^{12}$ Mendes e Faria (2018, p. 224) afirmam que a medida de segurança, ao seguir uma lógica manicomial preconizada pelo Código Penal, promove exclusão e estigmatização reproduzindo das relações sociais marcadas pela desigualdade.

${ }^{13}$ Em sentido similar, Carvalho e Weigert (2013, p. 286) entendem que a partir da Lei da Reforma Psiquiátrica, a validade dos preceitos do Código Penal resta passível de questionamento, inclusive ao ponto de fundamentar o entendimento de que o artigo 26 da lei penal substantiva não teria sido recepcionado.
} 
incompleto ou retardado, e a capacidade de entender o caráter ilícito do fato ou de determinarse de acordo com esse entendimento, à época do fato. Primeiramente, tem-se a presença de transtornos mentais e, em segundo lugar, e capacidade de volição do agente é determinada, de modo que se tem a adoção do critério biopsicológico da inimputabilidade penal (BARRETO, 2019).

Costa (2008), em sua análise, indica ser inexplicável que alguém possa ser privado de sua liberdade quando não preencher todos os requisitos do crime, especialmente a imputabilidade, que compõe a própria culpabilidade; desse modo, se a segregação do agente criminoso é admitida na aplicação de uma pena privativa de liberdade, torna-se incoerente na aplicação de uma medida de segurança, onde a sanção penal se restringe somente ao campo da tipicidade e da ilicitude.

Neste ponto, novamente, faz-se referência a Veloso (2011, p. 139-144), que assevera que "o princípio da culpabilidade deve ser entendido como um instrumento de limitação da pena, com fundamento constitucional na dignidade da pessoa humana", por impor que "o autor de um fato imputado como crime não será punido com o objetivo de prevenção, relegando sua dignidade como pessoa humana".

Netto e Naves (2018), de outro lado, destacam o problema da desproporcionalidade entre o fato e a sanção que o inimputável recebe, por decorrência da exceção ao princípio da culpabilidade. Não sendo a medida de segurança guiada na correspondência da culpabilidade do agente, a sanção penal se revela, por via de consequência, muito mais extensa, implicando numa desproporcionalidade da resposta penal em relação à conduta, como ocorre em casos nos quais condutas tipificadas como lesão corporal, por exemplo, recebem medidas de segurança que duram anos a mais do que o máximo de pena em abstrato do tipo penal permitiria.

Se a determinação da sanção, nesses casos, é a periculosidade, e esta é entendida como uma característica inerente ao indivíduo, por ser correspondente a sua própria loucura à persistência dos sintomas, controlados ou não -, então a tendência da medida é de manter o agente inimputável sob tutela do sistema penal por tempo indeterminado, não vinculado, necessariamente, ao ilícito praticado, de modo que o perigo à sociedade que o louco representa independe da gravidade da conduta (NETTO e NAVES, 2018).

Brisset e Juncal (2018) apontam que o funcionamento das medidas de segurança encontra raízes no direito penal do autor, onde sujeitos recebem sanções penais em 
conformidade não com o que fizeram, mas sim, conforme aquilo que são, etiquetados como doentes mentais perigosos, incapazes de responderem pelos atos que praticam. No direito penal de autor, a pessoa é acusada e condenada por sua condição existencial, situação não diferente da medida de segurança, onde o indivíduo é absolvido pelo que é, e sujeito a diversas consequências "jurídico-terapêuticas" que não podem ser consideradas melhores que a pena.

Além disso, a nível conceitual ${ }^{14}$, é notável que a periculosidade se apresenta como um juízo de certeza baseado numa predição abstrata acerca do comportamento humano, pautada na discriminação entre o que seria normal ou não. Fragoso (2003, p. 246) aponta que o critério legal da medida de segurança "concebe a psicologia da ação de forma que não corresponde à realidade", afirmando que "são irrespondíveis as indagações sobre a capacidade de entendimento do injusto e sobre a capacidade de determinação conforme tal entendimento".

A imprecisão conceitual da periculosidade leva Roesler e Lage (2013) a afirmar que há uma grave carência de argumentos lógicos aptos a justificar a validade da noção de periculosidade e sua respectiva aplicação jurídica como fator-chave da aplicação de medidas de segurança no ordenamento jurídico pátrio ${ }^{15}$. Como se sabe, o oferecimento de uma fundamentação rigorosamente idônea constitui etapa necessária para as decisões estatais no Estado Democrático de Direito, tendo em vista que é a discussão sobre a razão dos fundamentos decisórios que permitirá o controle do poder, o que é prejudicado pela noção de periculosidade.

Em somatório, as análises sobre o tema apontam que a periculosidade não tem fundamento científico: é um conceito de conteúdo jurídico - visto que, em função de consistir no risco de reiteração criminosa, depende do conceito de crime, que é normativo, e não

\footnotetext{
${ }^{14}$ Faz-se referência ao esforço observado no trabalho de Caetano (2017), que se volta à tentativa de delimitar um conceito propriamente científico e seguro para a noção de periculosidade. Tendo estudado as formulações de Sebastián Soler, Filippo Grispigni, Jiménez de Asúa, Alfredo Rocco, Raffaele Garofalo, e Enrico Ferri, o autor conclui, com apoio em Kátia Mecler, que a noção de "temibilidade" do agente, exposta desde Garofalo, foi o conceito-chave que antecedeu a teoria da periculosidade. Assim, a defesa social proposta por esses autores positivistas é concebida como o direito do Estado de defender-se dos indivíduos perigosos, concepção que se consolida com O Homem Delinquente de Cesare Lombroso, e a emergência da ideia do "criminoso nato".

${ }^{15}$ Roesler e Lage (2013) verificam ainda que o tratamento dispensado aos casos analisados é incoerente, não uniforme e, destarte, se inscreve na contraposição de dois paradigmas distintos e contraditórios: aquele presente na redação do Código Penal, que se demonstra incompatível com o paradigma que norteia a Lei da Reforma Psiquiátrica, informado pela luta antimanicomial. 
natural - que, para se manifestar, depende da junção da ideia de loucura com a verificação da prática de um crime (CAETANO, 2017).

À guisa de conclusão, percebe-se que a medida de segurança: não apresenta fundamentos idôneos para confirmar a necessidade de sua aplicação, não se conforma com a racionalidade do direito penal, e entra em choque com o paradigma que norteia o ordenamento jurídico a respeito do tratamento de pessoas portadoras de transtornos mentais. Assim encerrando o desenvolvimento da análise, segue-se às considerações finais.

\section{CONSIDERAÇÕES FINAIS}

Como resposta ao problema apresentado na introdução, é possível afirmar, a partir de uma breve incursão de teor histórico e crítico, que a medida de segurança é oriunda do enfoque etiológico observado na Criminologia Positivista, e que o direito penal, no contexto atual do Estado Democrático de Direito, não se fundamenta mais em tal paradigma, apresentando um viés normativo na teoria do delito, de modo a limitar as arbitrariedades e a seletividade do poder punitivo - podendo-se concluir que a medida de segurança não está em concordância com os fundamentos do direito penal, o que confirma a hipótese apresentada.

Pelas referências críticas adotadas, a lógica da medida de segurança trata o portador de doença mental como alguém que carrega um potencial criminoso, de modo que a imposição de riscos ao meio e a si mesmo é encarada como condição de sua própria existência. A resposta penal, portanto, não se apresenta como proporcional à culpabilidade do indivíduo, mas se configura, neste cerne, como forma de amenizar o risco que é visto como inerente ao louco criminoso, entendido como uma pessoa que cometeu um crime e poderá, a qualquer momento, voltar a fazê-lo, porque louca.

É perceptível que a produção teórica do Direito Penal, historicamente, supera o paradigma etiológico da criminalidade, se direcionando ao enfoque da reação social, tomando o objeto do fenômeno criminal como uma realidade normativa, e não, natural. Do mesmo modo que o paradigma etiológico encontra dificuldades em se sustentar diante da perspectiva normativa e analítica de delito, a noção de periculosidade é contraditória ao entender que exista uma tendência natural de um determinado ser humano se comportar de forma ilícita.

Destarte, a ideia de que o crime seja resultado da formação biológica individual de algumas pessoas vai de encontro ao conjunto de teorias que informa a dogmática penal e, em 
última análise, contradiz os paradigmas mais recentes, oriundos das bases constitucionais do Estado de Direito, referentes não apenas à limitação de arbitrariedades do poder punitivo estatal, mas também à luta antimanicomial que se expressou na legislação mais recente, de 2001, mas não chegou a impactar os dispositivos penais que tratam da questão.

Nesse âmbito, verifica-se que o fundamento da culpabilidade penal é adequado às matrizes do controle social realizado pelo Estado, enquanto que a noção de periculosidade, por outro lado, apresenta diversas inconsistências. Com isso, resta perceptível que a vinculação constitucional do ordenamento jurídico permeia toda a gama das críticas, assim como ocorre com a fundamentação teórica do Direito Penal, de modo que as observações realizadas no último capítulo do artigo estão intrinsecamente relacionadas.

Mesmo uma análise perfunctória já é capaz de conjugar o posicionamento crítico com a compreensão constitucional do ordenamento jurídico, de modo a possibilitar a identificação de impropriedades que confirmam a hipótese explorada. Considerando-se que o presente trabalho resulta de pesquisas preliminares sobre o assunto, é possível afirmar que incursões mais aprofundadas nos temas das bases teóricas do Direito Penal em vigor poderão oferecer respostas sistêmicas e adequadas acerca das contradições e impropriedades que se exsurgem associadas ao instituto da medida de segurança e sua aplicação.

Ao final, e sem esgotar o tema, o qual, dada sua relevância, exige maiores pesquisas e incursões acadêmicas, é importante destacar que se toma como necessária a resposta estatal à questão do inimputável que comete ato ilícito, dado o papel assumido pelo Estado de resolver conflitos sociais e promover a segurança jurídica; no entanto, pela pesquisa realizada, verifica-se que tal resposta não há de ser pautada na vaga noção de periculosidade, que vai de encontro à coerência do ordenamento jurídico deste Estado Democrático de Direito. 


\section{REFERÊNCIAS}

ANDRADE, Vera Regina Pereira de. Do paradigma etiológico ao paradigma da reação social: mudança e permanência de paradigmas criminológicos na ciência e no senso comum.

Sequência: Estudos Jurídicos e Políticos, Florianópolis, p. 24-36, jan. 1995. ISSN 2177-7055. Disponível em: <https://periodicos.ufsc.br/index.php/sequencia/article/view/15819>. Acesso em: mar. 2020.

ANITUA, Gabriel Ignacio. Histórias dos pensamentos criminológicos. Rio de Janeiro: Revan, 2008.

BARATTA, Alessandro. Criminologia crítica e crítica do Direito Penal. Trad. Juarez Cirino dos Santos. 3. ed. Rio de Janeiro: Editora Revan - Instituto Carioca de Criminologia, 2002.

BARRETO, Rodrigo Silva. Entre Expansão ou Delimitação do Critério Biológico da Inimputabilidade Penal do Art. 26 do CP. Revista Magister de Direito Penal e Processual Penal - Ano XV - N 90, Jun-Jul 2019.

BECCARIA, Cesare. Dos delitos e das penas. São Paulo: Pillares, 2013.

BOBBIO, Norberto; MATTEUCCI, Nicola; PASQUINO, Gianfranco. Dicionário de política. 11. ed. Brasília: Editora Universidade de Brasília, 1998. Vol. 1: 674 p.

BOBBIO, Norberto. $O$ futuro da democracia: uma defesa das regras do jogo. Tradução de Marco Aurélio Nogueira. Rio de Janeiro: Paz e Terra, 1997. (Pensamento crítico, 63)

Teoria geral da política: a filosofia política e as lições dos clássicos. BOVERO, Michelangelo (org.). Tradução de Daniela Beccaccia Versioni. Rio de Janeiro: Elsevier, 2000.

Estado, governo, sociedade: por uma teoria geral da política. Tradução Marco Aurélio Nogueira. Rio de Janeko: Paz e Terra, 2007 (Coleção Pensamento Crítico, 69).

BOVERO, Michelangelo. Para uma teoria neobobbiana da democracia. Tradutor Marcelo de Azevedo Granato. São Paulo: FGV Direito SP, 2015.

BRANCO, Thayara Castelo. A (des)legitimação das medidas de segurança no Brasil. 2. ed. Porto Alegre: Livraria do Advogado Editora, 2019.

. O estado penal-psiquiátrico e a negação do ser humano

(presumidamente) perigoso. Revista de Criminologias e Políticas Criminais. e-ISSN: 25260065. Maranhão, v. 3, n. 2, p. 19 - 32, Jul/Dez, 2017.

BRISSET, Fernanda Otoni de Barros; JUNCAL, Regina Geni Amorim. O que diriam os "loucos"? Revista Brasileira de Ciências Criminais. vol. 144. ano 26. p. 441-473. São Paulo: Ed. RT, junho 2018. 
CADEMARTORI, Daniela Mesquita Leutchuk de; CADEMARTORI, Sergio. A relação entre Estado de direito e democracia no pensamento de Bobbio e Ferrajoli. Revista Sequência, n. 53, p. 145-162, dez. 2006.

CAETANO, Haroldo. Direito Penal perigoso - ou, afinal, perigoso é mesmo o louco? Revista Magister de Direito Penal e Processual Penal. No 76, Fev-Mar/2017.

CARVALHO, Salo de; WEIGERT, Mariana de Assis Brasil e. Reflexões iniciais sobre os impactos da lei 10.216/01 nos sistemas de responsabilização e de execução penal.

Responsabilidades, Belo Horizonte, v. 2, n. 2, p. 285-301, set. 2012/fev. 2013.

CARVALHO, Salo de. Substitutivos penais na era do grande encarceramento. Revista de Estudos Criminais, ano XII, n. ${ }^{\circ}$ 55, p. 146-171, 2014.

COSTA, Cezar Augusto Rodrigues. A Superveniência de Doença Mental no Condenado pela Prática de Crime, uma Necessária e Urgente Mudança a que deve se Submeter o Código Penal. Revista da EMERJ, v. 11, nº 44, 2008.

CUNHA, Rogério Sanches. Manual de direito penal: parte geral. 4. ed. rev., ampl. e atual. Salvador: JusPODIVM, 2016. 560 p.

FONSECA, Maria Guadalupe Piragibe da. Iniciação à pesquisa no direito: pelos caminhos do conhecimento e da invenção. Rio de Janeiro: Elsevier, 2009.

FOUCAULT, Michel. Vigiar e Punir: nascimento da prisão. 42. ed. Petrópolis: Vozes, 2014.

FRAGOSO, Heleno Cláudio. Lições de direito penal. 16. ed. Rio de Janeiro: Forense, 2003.

GUIMARÃES, Cláudio Alberto Gabriel; BRANCO, Thayara Castelo; GODOY, Samanta Frazão Cruz de. Estado e controle social na sociedade contemporânea: entre a legitimação e a crítica abolicionista. Revista do Ministério Público do Estado do Maranhão: Juris Itinera, v. 1, n. 1 (jan.-dez. 1991). São Luís: Procuradoria-Geral de Justiça, 2018.

GUIMARAES, Cláudio Alberto Gabriel. Funções da pena privativa de liberdade no sistema penal capitalista. 2. ed., Rio de Janeiro: Revan, 2007. 350 p.

. Reflexões acerca do controle social formal:

rediscutindo os fundamentos do direito de punir. Revista da Faculdade de Direito da UERJ, [S.1.], n. 23, jul. 2013. ISSN 2236-3475. Disponível em: <https://www.epublicacoes.uerj.br/index.php/rfduerj/article/view/4894>. Acesso em: 17 maio 2020. doi: https://doi.org/10.12957/rfd.2013.4894.

GUSTIN, Miracy Barbosa de Sousa; DIAS, Maria Tereza Fonseca. (Re)pensando a pesquisa jurídica: teoria e prático. $3^{\circ}$ ed. rev. e atual. pela NBR 14.724, de 30/12/05, da ABNT. Belo Horizonte: Del Rey, 2010, 256p. 
MACHADO, Bruno Amaral; MESSERE, Fernando Luiz de Lacerda. Loucura, direito penal e psiquiatria: programação jurídica entre ruídos e acoplamentos. Revista Brasileira de Ciências Criminais. vol. 157. ano 27. p. 51-84. São Paulo: Ed. RT, julho 2019.

MARCONI, Marina de Andrade; LAKATOS, Eva Maria. Fundamentos de metodologia científica. 5. ed. São Paulo: Atlas, 2003.

MENDES, Soraia da Rosa; FARIA, Gustavo Dalul. A (dis)funcionalidade da medida de segurança no paradigma da reforma psiquiátrica. Revista Brasileira de Ciências Criminais. vol. 144. ano 26. p. 217-250. São Paulo: Ed. RT, junho 2018.

MINAYO, Maria Cecília de Souza. Ciência, técnica e arte: o desafio da pesquisa social. In: MINAYO, Maria Cecília de Souza (org.). In: Pesquisa Social. Teoria, método e criatividade. 18 ed. Petrópolis: Vozes, 2009.

NETTO, Menelick de Carvalho; NAVES, Letícia. A punição da loucura: as decisões do Supremo Tribunal Federal após a Lei da Reforma Psiquiátrica. Revista Brasileira de Ciências Criminais. vol. 144. ano 26. p. 183-215. São Paulo: Ed. RT, junho 2018.

ROESLER, Claudia Rosane; LAGE, Leonardo Almeida. A argumentação do STF e do STJ acerca da periculosidade de agentes inimputáveis e semi-imputáveis. Revista Brasileira de Ciências Criminais. vol. 105. ano 21. São Paulo: Ed. RT, nov-dez, 2013.

SANTOS, Juarez Cirino dos. Direito penal: parte geral. 6. ed., ampl. e atual. Curitiba, PR: ICPC Cursos e Edições, 2014, 739 p.

SILVA, Aline Reis da; CAMPOS, Bruno da Silva; MOSCON, Raquel Fabris; COSTAMOURA, Renata. Do silenciamento e segregação à responsabilidade: por um tratamento renovado para o psicótico em conflito com a lei. Revista Brasileira de Ciências Criminais. vol. 144. ano 26. p. 251-277. São Paulo: Ed. RT, junho 2018.

VELOSO, Roberto Carvalho. Crimes tributários. São Paulo: Quartier Latin, 2011. 288 p.

ZAFFARONI, Eugenio Raul; PIERANGELI, José Henrique. Manual de direito penal brasileiro: volume 1 - parte geral. 9. ed. rev. e atual. São Paulo: Editora Revista dos Tribunais, 2011.

ZAFFARONI, Eugenio Raul. Em busca das penas perdidas: a perda da legitimidade do sistema penal. Trad. Vania Romano Pedrosa, Amir Lopez da Conceição. 5. ed. Rio de Janeiro: Revan, 2001.

O inimigo no direito penal. Rio de Janeiro: Revan, 2014. 